\title{
The possible mechanisms of subretinal fluid resolution after vitrectomy
}

\author{
Yusuke Ichiyama $^{1} \cdot$ Masahito Ohji $^{1}$
}

Received: 9 March 2016 / Accepted: 15 March 2016/Published online: 23 March 2016

(C) Springer-Verlag Berlin Heidelberg 2016

To the Editor:

We wish to thank Drs. Kaya and Aksoy for their interest and questions regarding our report on the effectiveness of vitrectomy in diffuse diabetic macular edema [1].

In our study, we found that vitrectomy was effective for the treatment of diffuse diabetic macular edema, particularly in eyes with subretinal fluid (SRF). As the commenters indicated, SRF may be associated with impairment of the outer blood retinal barrier or of pump function of retinal pigment epithelium (RPE). However, it is still unknown why dysfunction of RPE had developed in these patients with diabetic mellitus, so we cannot provide a robust answer as to why vitrectomy was effective for the resolution of SRF. Several possible reasons for this could be suggested, as follows: First, vitrectomy might improve the oxygenation of ischemic RPE and might increase the ability to pump fluid. Previous studies have demonstrated the decreased ability of RPE to pump fluid in hypoxic settings $[2,3]$. In patients with diabetic mellitus, RPE might be occurring in a hypoxic setting, although choroidal blood flow is high. Second, induction of posterior vitreous detachment (PVD) might improve the function of the outer retinal barrier. Previous reports demonstrated that vitreomacular adhesion and associated traction was strongly associated

Yusuke Ichiyama

ichiyama@belle.shiga-med.ac.jp

1 Department of Ophthalmology, Shiga University of Medical Science, Seta Tsukinowacho, Otsu, Shiga 520-2192, Japan with the progression of neovascular age-related macular degeneration [4], and vitrectomy could be a suitable treatment [5]. These results suggested that surgical induction of PVD could have positive influence on the function of the outer retinal barrier. Finally, vitrectomy might increase external stimuli to RPE, resulting in enhanced RPE function, as Drs. Kaya and Aksoy suggested. However, all possible reasons described above have insufficient evidence for their establishment. Further research is needed to reveal the pathogenesis of diabetic macular edema, including SRF and the mechanisms of SRF resolution after vitrectomy. We really hope that our report can be of assistance in this work.

Acknowledgments None of the authors have any financial/conflicting interests to disclose.

\section{References}

1. Ichiyama Y, Sawada O, Mori T, Fujikawa M, Kawamura H, Ohji M (2016) The effectiveness of vitrectomy for diffuse diabetic macular edema may depend on its preoperative optical coherence tomography pattern. Graefes Arch Clin Exp Ophthalmol. doi:10.1007/ s00417-015-3251-4

2. Grimes PA, Laties AM (1980) Early morphological alteration of the pigment epithelium in streptozotocin-induced diabetes: increased surface area of the basal cell membrane. Exp Eye Res 30(6):631-639

3. Kirber WM, Nichols CW, Grimes PA, Winegrad AI, Laties AM (1980) A permeability defect of the retinal pigment epithelium. Occurrence in early streptozotocin diabetes. Arch Ophthalmol 98(4):725-728

4. Lee SJ, Lee CS, Koh HJ (2009) Posterior vitreomacular adhesion and risk of exudative age-related macular degeneration: paired eye study. Am J Ophthalmol 147:621-626

5. Roller AB, Mahajan VB, Boldt HC, Abramoff MD, Russell SR, Folk JC (2010) Effects of vitrectomy on age-related macular degeneration. Ophthalmology 117:1381-1386 